sustained a concussion between 2010\%-2013. 84\% of respondents noted they had not sustained a concussion during 2014. However, there were a significant number of semi-professional defenders who sustained a concussion that year. There was a higher rate of self-reported concussion amongst League of Ireland footballers in 2014 than in a similar study carried out on professional footballers in Italy in 2009. Respondents were more likely to report a concussion to a physiotherapist or doctor. Respondents were asked to identify a reason for not reporting a concussion, the most prominent being that players lacked unawareness of concussion impacts. Conclusion Concussion reporting by mainstream media coupled with an introduction of concussion awareness programmes has resulted in a general increase in personal safety knowledge and awareness of concussion amongst Irish footballers. Further studies are needed focussing on safety culture and occupational safety and health awareness is raised in the professional sporting sector.

\section{HAZARDOUS WORK: A LOOK AT THE SAFETY AND HEALTH AT WORK OF GARBAGE COLLECTORS IN ASUNCION, PARAGUAY, 2013-2014}

${ }^{1} \mathrm{~L}$ Flores, ${ }^{2} \mathrm{D}$ Carvalho, ${ }^{3} \mathrm{~K}$ Radon. ${ }^{1}$ Investigación para el Desarrollo. DIGESA. Paraguay; ${ }^{2}$ International Master Occupational Safety and Health of $\mathrm{CIH}$; ${ }^{3}$ International Master Occupational Safety and Health of CIH. Institute for Occupational, Social and Environmental Epidemiology and Net Teaching Unit. LMU

\subsection{6/oemed-2018-ICOHabstracts.70}

Introduction Garbage collector is a high-risk job, with exposure to a variety of occupational and non-occupational factors. Total injury rates of occupational accidents in these workers are not known in Paraguay, the aim of the study was to estimate and to compare the prevalence of accidents at work in formal and informal garbage collectors of Asunción, Paraguay. Methods A cross-sectional study was conducted among 186 formal and 123 informal garbage collectors (response 84.5\%, 56\%). The 12-months-prevalence of occupational accidents and its association with socio-demographic factors (age, gender, education), employment and working conditions, work shifts, safety (exposure to unprotected openings and holes, ladders, slopes, a lack of cleanliness, clutter, poor lighting, lack of protection, and tools in poor condition), alcohol consumption, mental health, use of personal protective equipment (PPE) and manual handling of waste were examined using a structured questionnaire. Descriptive statistics, bivariate analysis (chi square test) and adjusted logistic regression models were carried out.

Results Formal workers were younger $(57 \%$ over 40 years old), all male and better educated (82\% completed the first grade), compared to the informal group ( $7 \%$ over 40 years old, 68\% males and 30\% completed the first grade). The 12 months-prevalence of occupational accidents among formal garbage collectors was $37.5 \%$ vs $29.5 \%$ among informal garbage collectors $(p=0.1)$. Likewise, after adjustment for potential confounders no statistically significant difference between the two groups was found (Odds $1.8 ; 95 \% \mathrm{CI}: 0.82$ to 3.88 ). Significant risk factors for 12 months prevalence of accidents were lack of gloves (1.84; CI: 1.01 to 3.05$)$ and poor safety conditions at the workplace (2.44; CI: 1.3 to 4.7$)$.

Conclusion Prevalence of accidents at work among garbage collector is high. Workplace safety measures and use of gloves decrease the risk of accidents, therefore researches and interventions on occupational health related to this activity are necessary.

\section{IMPACT OF PSYCHOSOCIAL AND ORGANISATIONAL FACTORS IN A 12 YEARS ACCIDENTOLOGY FOLLOW UP ANALYSIS IN A GAS COMPANY}

${ }^{1} J u l i a ́ n$ Cukier, ${ }^{2}$ Myriam Villegas Orué, ${ }^{2}$ María Fernanda Palacio, ${ }^{2}$ Diego Marmanelli, ${ }^{3}$ Cecilia Colautti*, ${ }^{3}$ Javier Naveros. ${ }^{1}$ Argentinean Association of Health Promotion, TGS (GaS Transporter from the South), Buenos Aires, Argentina; ${ }^{2} T G S$ (Gas Transporter from the South), Buenos Aires, Argentina; ${ }^{3}$ Argentinean Association of Health Promotion, Buenos Aires, Argentina

\subsection{6/oemed-2018-ICOHabstracts.71}

Introduction Different deficiencies contribute to the occurrence of accidents or safety incidents, so detecting, analysing and modifying them will be decreasing worker's unsafe conditions and behaviours that increase the probability of an accident. Studies indicate that, in a high percentage, $85 \%$ to $90 \%$ of accidents, the human factor is present.

Methods Retrospective analysis of work accidents reported by the Company was made in the period between 2003 and 2015. An accidentology analysis is presented in a natural gas transportation company with 956 employees with a 9,000 km pipeline. Different factors involved in the production of accidents were considered, caused by 'failures in the security system' of the organisation. These failures include: defects in the design of technology, preventive measures in operations to be carried out, worker protection, inadequate work planning and lack of risk controls, and specially associated with 'human factors'.

Result During the period 2003-2015, there were 272 accidents, at a rate of 22.6 accidents per year. 51\% of accidents do not show unsafe conditions. Among the personal and organisational factors were involved in the accidents specially lack knowledge and/or lack of ability, deficiency in supervision and leadership, shortcomings in work procedures, lack of control in the use of tools or equipment.

Discussion It is often observed that the human factor (such as workers who are going through personal crises, partners, relatives, etc.) is often a fundamental variable for understanding accidents and designing preventive programs.

\section{HARMONISING THE LAW AND PRACTICE: OSH PRINCIPLES AND FUNDAMENTALS IN THE PHILIPPINES}

RA Asuncion. School of Labour and Industrial Relations, University of the Philippines Diliman

\subsection{6/oemed-2018-ICOHabstracts.72}

Introduction In 2015, the Philippine Statistics Authority (PSA) reported that there are 900,914 establishments in the Philippines. To ensure the safety and health of workers in these establishments, the Department of Labour and Employment (DOLE) is mandated with the overall administration and enforcement of $\mathrm{OSH}$ in the country.

However, while the Philippines has a concrete legal framework on OSH as well as a central government agency tasked to implement it, the annual accident and medical reports based on Work Accident and Illness Report (WAIR), the Annual Medical Report AMR), and the nationwide sampling survey of the Bureau of Labour and Employment Statistics (BLES) put to question the effectivity of the programs of DOLE as well as other government agencies in implementing OSH standards. This study looked into the challenges, issues and concern in managing $\mathrm{OSH}$ in the Philippines. 
Methods Document analysis and interviews were conducted to various duty of care bearers.

Results The high incidence in occupational accidents, injuries and diseases is a manifestation that the battle towards decent work and safe work environments in the Philippines has a long way to go. The discrepancy on the law versus practice of OSH Standards in the Philippines is evident. The number of establishments, the archipelagic nature of the country's geography, the low awareness on $\mathrm{OSH}$, and the lack of manpower from government agencies are just some major reasons why managing OSH in the Philippines is a very daunting task. Conclusions The nature of prevention measures on $\mathrm{OSH}$ in the Philippines can be described as a combination of both reactive and proactive policies. Considering the complexity of the challenges, issues and concerns involved, a holistic, integrated approach is therefore needed to upgrade the OSH situation in the Philippines.

\section{THE IMPACT OF SUSTAINED HOT WEATHER ON RISK OF ACUTE WORK-RELATED INJURY IN MELBOURNE, AUSTRALIA}

${ }^{1} \mathrm{JA}$ Mclnnes, ${ }^{1} \mathrm{EM}$ MacFarlane, ${ }^{1} \mathrm{MR}$ Sim* ${ }^{*}{ }^{1,2} \mathrm{P}$ Smith. ${ }^{1}$ Monash University Centre for Occupational and Environmental Health, Melbourne, Australia; ${ }^{2}$ Institute for Work and Health, Toronto, Canada

\subsection{6/oemed-2018-ICOHabstracts.73}

Introduction Increasing global temperatures will expose workers to hot days more often. The aim of this study was to quantify the impact of exposure to consecutive days of hot weather on the risk of work-related injury in Melbourne, Australia.

Methods A time-stratified case crossover study design was utilised to examine the association between 2 and 3 consecutive days and 2 and 3 consecutive nights of hot weather and risk of work-related injury, using definitions of hot weather ranging from the 60th to the 95th percentile of daily temperatures for the Melbourne metropolitan area, 2002-2012. Workers' compensation claim data were used to identify cases of workrelated injury.

Results Overall, 2 and 3 consecutive days of hot weather was associated with an increased risk of injury for workers. This effect became apparent at $27.6^{\circ} \mathrm{C}$, equivalent to the 70 th percentile of maximum temperature distributions during the study period. Exposure to three days of hot weather and the highest temperatures was associated with the strongest effect, with a $15 \%$ increased risk of injury (OR: $1.15,95 \% \mathrm{CI}: 1.01$ to 1.30) for workers exposed to temperatures $\geq 33.3^{\circ} \mathrm{C}$ (90th percentile) for 3 consecutive days, compared to those who were not. At a threshold of $35.5^{\circ} \mathrm{C}$ (95th percentile) there was no significant association between temperature and injury for either 2 or 3 consecutive days of heat. No consistent pattern was observed for hot nights, either with increasing levels of the temperature threshold or between two and three hot nights of exposure.

Conclusions Significant associations between consecutive days of hot weather and risk of work-related injury were apparent at relatively mild temperatures. These findings suggest warnings to minimise injury risk to workers from hot weather should be given and prevention protocols initiated when consecutive days of temperatures lower than extreme temperatures are forecast and before extreme temperatures are reached.
153 ORGANISATIONAL SOCIAL CAPITAL: THE MISSING LINK BETWEEN ORGANISATIONAL CULTURE AND SAFETY AWARENESS

${ }^{1}$ Dirk Van de Walle, ${ }^{1,2}$ Philippe Kiss, ${ }^{1,2}$ Marc De Meester. 'Securex Health and Safety, Drongen, Belgium; ${ }^{2}$ Department of Public Health, Ghent University, Ghent, Belgium

\subsection{6/oemed-2018-ICOHabstracts.74}

Introduction Occupational Health and Safety has known several waves to prevent injuries and worker's drop out. First, mainly technical measures were implemented. In the 1990's management systems introduced organisational measures. More recently, one became aware of the vital role of the individual (who uses the techniques according to the management system). The worker's behaviour (safety awareness) is the missing link between technical and organisational measures. The aim was to explore the relation between organisational culture and safety awareness.

Methods 17400 employees, working in 128 (private and public) organisations $(79.0 \%$ participation), filled out a self-completed questionnaire. Group level analyses on company level were performed to explore the relationship between organisational social capital (OSC) and 4 safety parameters: importance of safety in the organisation, presence of clear safety rules, recognition of working practices and knowing whom to turn to.

Organisations were divided according to size $(<50,50-99$, 100-199, $\geq 200$ employees). 113 organisations were grouped into 10 similar activity groups.

Prevalence rates of the considered safety parameters were calculated by organisation size and activity group.

Relationships between OSC and safety parameters were explored within same activity groups by correlation coefficients.

Results Analyses by company size revealed similar patterns in safety parameters: companies with $<50$ employees scored best, followed by companies with 100-199 employees, companies with 50-99 employees and worst in companies with $\geq 200$ employees.

Safety parameters scored best in construction and industries, while information and communication companies scored worst.

Depending on activity group and considered safety parameter highly significant correlations were found with OSC $\left(\mathrm{R}^{2}\right.$ reaching up to 0.87 ).

Discussion The results indicated a clear link between organisational culture and safety awareness according to company size, but regardless of activity group. The strong relationship between OSC and safety parameters indicates a predominant role of OSC within a preventative approach in safety management.

\section{THE VALUE OF SAFETY AND HEALTH TO SOCIETY - NEW GLOBAL AND EUROPEAN ESTIMATES OF ECONOMIC IMPACT}

${ }^{1}$ Dietmar Elsler, ${ }^{2}$ Jukka Takala, ${ }^{3}$ Jouko Remes. ${ }^{1}$ EU-OSHA, Bilbao, Spain; ${ }^{2}$ WSH, Singapore; ${ }^{3} \mathrm{FlOH}$, Helsinki, Finland

\subsection{6/oemed-2018-ICOHabstracts.75}

Introduction Establishing a reliable and comprehensive estimate of the cost to society of all occupational accidents and work- 